\title{
The management of medical records in the context of service delivery in the public sector in KwaZulu-Natal, South Africa: the case of Ngwelezana hospital
}

\author{
Lungile. P. Luthuli ${ }^{1}$ and Trywell Kalusopa ${ }^{2}$ \\ lungile.dapresh.luthuli@gmail.com ORCID: orcid.org/0000-0002-4310-8148 \\ kalusopat@unizulu.ac.za ORCID: orcid.org/0000-0001-9331-1307
}

\begin{abstract}
Received: 16 June 2017
Accepted: 4 November 2017

In South Africa, under the public sector reforms, issues of public service delivery are anchored to by Batho Pele principles that were introduced in 1997 to entrench public service delivery in order to underscore transparency and accountability. Among other issues, the Batho Pele principles espouse efficient and effective public health sector delivery services which, in context, can be propelled by a reliable and trustworthy medical records regime. Several studies conducted at national level and particularly at provincial level (Limpopo, Gauteng, Eastern Cape and Western Cape) point to the fact that good and efficient records management is critical in realising accountable and transparent health service delivery. There has been the recognition of this synergy between medical records management and service delivery, yet there are few empirical studies which examine the role of records management in KwaZulu-Natal province; more particularly, with specific reference to the Ngwelezana Public Hospital. This study, therefore, presents empirical results of an investigation into the implementation of good records management services and the extent to which this contributes to corresponding citizen satisfaction of good health delivery at the community level. The ultimate goal of the study is to understand the scale and dimension of good medical records management in determining issues of accountability in health care for citizens at local or community level in the quest for optimal health service delivery and governance. Overall, the evidence shows that poor records management could undermine the service delivery, particularly transparency and accountability in health delivery. The study endorses, based on best practice, recommendations that underscore good records management governance, recordkeeping system, records management technology and infrastructure, records archival processes, and records management human resource capabilities.
\end{abstract}

Keywords: Medical records management, public health accountability, public service delivery, public sector reform, KwaZulu-Natal, South Africa

\section{Introduction}

South Africa is one of the many developing countries that continues to battle with ways to improve state-owned facilities so that the best public service may be provided to its citizens. The issue of public service delivery remains a contentious issue in the country. Since the fall of apartheid, many citizens have complained about service rendered by various government facilities. Among other sectors of the economy, health service delivery continues to receive such attention. Numerous complaints have been presented regarding the poor service delivery at public hospitals. At the core of the delivery of service has been the need for effective records and information management delivery systems of reliable and authentic information so that patients are able to receive quality medical services. Issues of negligence and poor diagnosis and treatment have been linked several times to ineffective and poor record keeping (Marutha 2011, Katuu 2015, Pyrene 2015, Marutha 2016). Drawing on good records management principles and standards, this paper sought to establish the role of medical records in the delivery of public health services and systems at Ngwelezana Public Hospital.

Ngwelezana Public Hospital is based in the Umhlathuze area north-east of Durban, KwaZulu-Natal (KZN) province, South Africa. The hospital, a 554-bed space (Luthuli 2017), carries out a public health function under the government and is state-owned. It provides district, regional and tertiary health services to communities from the uThungulu, uMkhanyakude and Zululand regions. It is situated in the suburb of Ngwelezana which is five kilometres away from the town of Empangeni (Luthuli 2017). The hospital opened in 1970 as a convalescence hospital. In October 1977, all services were assumed by

1. Lungile. P. Luthuli is Lecturer the Department of Information Studies, University of Zululand, South Africa

2. Trywell Kalusopa is Professor in the Department of Information Studies, University of Zululand, South Africa 
the KZN government (Luthuli 2017). Ngwelezana Hospital was intended to be one of the tuberculosis settlements in the province. The hospital has grown to be one of the largest hospitals in the Umhlathuze area. The hospital has a staff complement of well over 1,200 and services about 7,700 patients per month, including referrals from other hospitals. The hospital has fourteen departments (Luthuli 2017). The hospital has a medical records management function that serves the community. However, over the past years, questions have been raised about the effectiveness of the records service in enabling the delivery of quality health care in the province (Luthuli 2017).

\section{Problem statement and specific objectives of the study}

The overarching problem that prompted this study is that, even though the role of medical records in public hospitals have been studied by several scholars (Khoza 2008, Katuu 2015, Marutha 2011, Marutha 2016, Ngulube 2012), in South Africa, insufficient attention has been paid to the KZN context; more particularly, at the Ngwelezana Hospital. For example, previous studies such as Katuu (2015) focused generally on public health institutions in South Africa and identified appropriate interventions to address the challenges facing records management in the health care system. Other studies, such as those by Pyrene (2015) and Marutha (2016), only focused on public health institutions in the Eastern Cape and Limpopo provinces respectively; Khoza (2008) reported negligence in private hospitals in Cape Town. It is apparent from the literature reviewed that there is little evidence of empirical studies carried out at Ngwelezana Hospital. Equally, there are few empirical studies in the KZN province that demonstrate the breakdown in the synergy between medical records management and service delivery. The researchers thus sought to examine the extent to which medical records were managed according to the best records management standards and practices in public hospitals to support service delivery with specific reference to Ngwelezana in the Umhlathuze area, KZN. It is hoped that the study will enlighten medical records managers, health practitioners and the public on the importance of the management of medical records within public hospitals based on records management principles guided by appropriate theory and international standards and practice. It is also hoped that medical records will be created and kept accordingly so as to improve health services delivery. The following were the specific objectives of the study:

- to establish the compliance with procedure tools in accordance with service delivery;

- $\quad$ to assess the required assistance from the records management unit for patients at the public hospital;

- $\quad$ to examine the location and length of retrieval of medical records at the public hospital;

- to establish patient satisfaction with records management at the public hospital; and

- to assess the impact of records management structure on service delivery.

\section{Literature review}

Medical records are a written account of a patient's examination and treatment that includes the patient's medical history and complaints; the physician's findings; and the results of diagnostic tests, procedures, medications and therapeutic procedures. Medical records are also known as 'patient records' (International Records Management Trust [IRMT] 1999: 10). Health service delivery cannot be determined without a functional records management service, thus implying that, with good records management, the level of performance of health delivery services or agencies can be adequately determined.

The IRMT (2009) defines records management as the task of ensuring that all recorded information, regardless of form and medium, is managed in an economical and efficient manner. Good records management governance, recordkeeping systems, records management technology and infrastructure, records archival processes and records management human resource capabilities are critical to the effective management of medical records. Records management policies, standards, procedures and tools provide a framework for the development and implementation of a records management programme together with commitment and buy-in from all stakeholders (ISO 15489-1: 2016). For an effective level of compliance, records management staff must be aware of their responsibilities to manage records, the recordkeeping system and recordkeeping procedures, including how to create and manage files, and their retention and destruction responsibilities. The IRMT (2009: 2) states that hospitals should employ qualified medical records managers to manage a centralised records management system. Green (2011: 10) posits that a centralised records system is one where records are put together in one place for easy access. A centralised filing system for medical records is also recommended by the International Records Management Trust (1999: 23).

Mampe (2013) and Luthuli (2017) note that records support accountability, security, integrity and comprehensiveness and are critical to effective service delivery to the community. The IRMT (1999: 1) agrees that, if records are not properly managed, health service may be affected in a negative way. An important element of records management is that records are created and kept so that they can be made available to their intended users whenever required (Shepherd and Yeo 2003). Shepherd and Yeo (2003: 130) suggest that an essential element in record registration is giving the record a unique 
identifier "that sets it apart from all other records within a records management system". Shepherd and Yeo (2003: 131) further posit that record registration is closely linked to the collection of records metadata and can occur at any level of aggregation such as at levels of "individual items, files, folders and records series".

A legal and regulatory framework is critical to records management governance. In South Africa, the formulation of the National Health Act (NHA) was meant to bring about uniformity and direction in the health service practice of the country, as stipulated and mandated in the Constitution and other laws related to service delivery (National Health Act, No. 61 of 2003: 2). The National Health Act stipulates that, in government health departments, a health record should be "created and maintained at that health establishment for every user of health services" and protected (South Africa 2003 Section 13 and 17). Furthermore, the National Health Act of South Africa 2003 Section 68 and Section 90 states that the Minister "may make regulations on how a particular record should be managed" (Katuu 2015: 125). The NHA guides institutions on how health departments should be governed in both public and private hospitals. The aim of the Act is to build a national health system that governs both public and private health services therefore ensuring that everyone has access to equal health services. It sets out the rights and duties of all health practitioners and protects the rights of children to basic nutrition and health care as well as those of vulnerable groups like women, older persons and people with disabilities (National Health Act, No. 61 of 2003). In terms of complaints, the law further states that in both the private and public health care institutions, any person has the right to lodge a complaint about the way they have been treated by health care providers. The system for lodging complaints must be visibly displayed by all medical establishments; each municipal area has its own system. Private institutions must allow for lodging of complaints with the head of the establishment. According to the Act, the framework for the health system is based on a decentralised model. This means that power, authority, and functions shift away from the national Department of Health, first to provincial departments and then to health districts (National Health Act, No. 61 of 2003). Regarding records management, the National Health Act, No. 61 of 2003 says a health establishment must ensure that health records are available when needed to protect users and the health establishment against risks of delayed, unsafe or inappropriate care. For the purposes of sub-regulation, the health establishment must:

- implement a record storage and retrieval system;

- appoint a trained and competent member of staff to oversee the information management department;

- train all managers in the use of and interpretation of information for the monitoring, evaluation, and planning of services;

- $\quad$ protect the confidentiality and security of health records with appropriate security control measures in records areas in line with the Protection of Personal Information Act, No. 4 of 2013);

- maintain an archival system for the stipulated duration of time according to the National Archives of South Africa Act, 1996 (Act No. 43 of 1996); and

- $\quad$ ensure the protection of health records from theft, fire or water damage.

In addition, the National Archives of South Africa Act, No. 43 of 1996 provides the legislative and legal framework for how records management practices in governmental bodies are regulated. The National Archives of South Africa Act, No. 43 of 1996 makes it clear that institutions dealing with health services must ensure that records relating to health services are created and maintained at that health institution for further service delivery. In the South African context, government departments are under legislative obligations to adopt a systematic and an organized approach to the management of records (Ngoepe 2008: 2).

Legislative framework is augmented by Batho Pele principles entrenching public service delivery. South Africa inherited a public service that was not people-friendly and staff lacked the skills and attitudes to meet the developmental challenges facing the country. In the struggle to transform the public service, there were calls to ensure that the public are served properly and that all staff work to their full capacity and treat state resources with respect (South Africa 1995). In that regard, the Batho Pele initiative was launched in 1997 to transform public service delivery at all levels (batho pele being a Sesotho word meaning 'people first'). Batho Pele was spearheaded by the Department of Public Service and Administration, thus giving continuity to the agenda of the Reconstruction and Development Programme of the early 1990s which was aimed at meeting the basic needs of all citizens. The Batho Pele White Paper (South Africa 1995) states that the South African public service will be judged by one criterion: its effectiveness in delivering services that meet the basic needs of all South African citizens. With regards to the management of records, some scholars have argued that the Batho Pele principles were coined to assist records handlers, as well as people dealing with the community, to employ Ubuntu in service delivery. Marutha (2011: 10) aptly underscores this argument with the following:

Effective and efficient records management will eventually lead to maximum compliance with Batho Pele principles since all eight principles are dependent on business records. The eight Batho Pele principles are consultation, service standard, access, courtesy, information, openness and transparency, redress 
and value for money. The South African government introduced the Batho Pele principles to transform public services and improve service delivery. Records management is implemented to ensure that relevant records and information are safely kept and made available when required or requested.

The above implies that records management plays a huge role in the community at large as it can be used as a reference when necessary in the current and future delivery of health services. It is therefore useful to assert that, while the literature reviewed underscores the fact that good medical care relies on well-trained doctors and nurses as well as highquality facilities and equipment, these, in return, rely on good record keeping (IRMT, 1999: 1). Without accurate, comprehensive, up-to-date and accessible patient case notes, medical personnel may not be able to offer the best treatment or may misdiagnose a medical condition (IRMT, 1999: 2). Good records can also ensure that the hospital administration runs smoothly and therefore saves time and other resources. Managing medical records, therefore, addresses the specific issues involved in managing clinical and non-clinical hospital records, indicating where approaches are needed to meet the specific requirements of records service within the hospital environment (IRMT 1999: 1). Furthermore, efficient accessibility to records will ensure a good service delivery at all times. Good quality medical records are an essential component of safe and effective healthcare but also have many secondary uses such as health system planning, management, quality control, public health monitoring, program evaluation, and research (Dunlay et al. 2008).

Accordingly, poor records management tends to affect patient care adversely since clinical treatment of patients is dependent on case histories contained in their medical files (Asunmo and Yaya 2016: 2). Literature reviewed shows similar challenges arising out of poor medical recordkeeping practice across Africa. In Zimbabwe, a study by Chikuni (2006) found that there was no effective storage of patients' records. As a result, it was the responsibility of patients to maintain and preserve their own patient records. According to Chikuni (2006), this practice slowed down the provision of health services because in most cases, patients felt it was a burden to carry around their medical records. As a consequence, medical staff could not effectively deliver health services since they had no records to inform their decisions. In Uganda, hospital staff appeared unaware of the importance of medical records to the treatment and follow-up of patients (Mayanja 2005: 11). In Ghana, the existing record keeping systems of some public hospitals were found not to be designed to collect information on some diseases, leading to poor monitoring, supervision, and decision-making (Adjei 2000: 5). A researcher at a rural hospital in Ethiopia described a similar challenge in which patient registration numbers were replicated, records were lost and patients were assigned new registration numbers, clinical information was recorded on loose scraps of paper, and medical records were poorly archived (Wong \& Bradley 2009: 3). In South Africa, Ngoepe (2004) documented that the Western Cape Government's Desai Commission reported that poor records management affected service delivery. Similarly, in North West and Gauteng provinces, unpaid patient bills from 1994 to 1999 totalling millions of rands had to be written off due to incomplete patient records.

Poor records keeping has been established as one of the causes of poor health service delivery in South Africa (Khoza 2008, Marutha 2011, Katuu 2015, Pyrene 2015, Marutha 2016). Studies conducted on medical records management by scholars such as Marutha (2011), Katuu (2015), and Pyrene (2015) all show that, due to poor records management, both the Departments of Health and Social Development in South Africa were experiencing various challenges as far as service delivery issues were concerned. The key to these challenges was the lack of commitment to implement the Public Service Commission (2012) recommendations on the Batho Pele principles. The Departments indicated that lack of funds was hampering the implementation of the Batho Pele principles (BPP Report Assessment, 2012: 87). Studies further showed that the Health Department, particularly in KZN, had been slowly improving service delivery in the areas of accessibility, courtesy, and consultation. Service users' views confirmed the improvements and benefits that they had experienced from the changes that were made to health service delivery. However, challenges were still identified in relation to information, service standards, openness and transparency, redress and value for money. As a result, service delivery was hampered in these areas. The findings also established that the lack of sufficient financial and human resources was the main constraint at the Department of Health in its quest for interventions to transform public service delivery.

It is evident that, for effective health service delivery, records need to be managed and protected to ensure accessibility at all times. Medical records serve as an invaluable tool within hospitals and the community in which they function and, in fact, epitomise a good health service delivery (Hajavi, Ebadi and Meidani 2005).

\section{Conceptual framework}

There are several contending theories and standards that guide the practice of records management: ISO 23081-1:2006, ISO 13008:2012 and ISO 30302:2015, to name a few. In this study, the records lifecycle theory, ISO 15489-1 (2016) was utilised. The records lifecycle is seen as a co-concept of records management (Chachage and Ngulube 2006: 3). The importance of the records lifecycle in this study is that it guides the understanding of the management of physical records. In that regard, it is suitable for this study as most public hospitals in the Umhlathuze area, in their quest for servicing the 
patients or community at large, are still predominantly using paper-based records (Luthuli 2017). In these institutions, large volumes of paper records are generated and used. The lifecycle concept was assumed to be valuable to the study as it allowed for the tracing of the records management processes through their whole lifecycle (Luthuli 2017). In that way, the study was able to establish current records management strategies, programs, and systems in records management in the context of service delivery in the Umhlathuze area. Authors such as Pyrene (2015) and Marutha $(2011,2016)$ observed that paper records are also dominant in public hospitals in the Western Cape and Limpopo provinces. Both studies used the records lifecycle as a theoretical framework.

ISO 15489-1 (2016) supplemented the records lifecycle because it provides the ideal framework for the creation, capture and management of records regardless of structure or form, in all types of business and technological environments over time. It gives guidance on how records management processes should function within an organisation and identifies the necessary results and outcomes to be expected. It reinforces the importance of records management by providing guidance on how records should be kept in an organisation. It also augments the role that records management can play in the strategic direction of an organisation by representing the close relationships between recordkeeping, accountability, risk management, information management and quality management. The ISO 15489-1 was therefore valuable in determining whether the records management practices, programs and standards in the hospitals are effective and efficient in supporting service delivery in Ngwelezana Public Hospital.

Further, in determining compliance in service delivery, the Batho Pele principles were used. Formulated in 1997, these principles underscore how to plan customer orientation to better service the public sector, based on eight tenets. Schalk (2003: 29) lists the Batho Pele principles as follows:

- consultation;

- service standards;

- access:

- courtesy;

- information;

- openness and transparency;

- redress; and

- value for money.

\section{Methodology}

The study utilised case study research design. Methodological triangulation of both quantitative and qualitative data collection methods, namely a semi-structured questionnaire, semi-structured interviews and observations, were adopted. Several researchers in records management such as Abankwa (1999), Kemoni (1999), Mampe (2013), Thanye (2014), Moatlhodi (2014) and Luthuli (2017) have used the case study method to study records management in the public sector. There are a number of reasons that can be attributed to the use of a case study approach. Kumar (2008) points out that a case study allows for a single phenomenon to be studied, putting the researcher in a better position to grasp the total complex world of organisational actions as they occur. A researcher is therefore able to understand how people work together in an organisation and how their relationships influence their work. Furthermore, a case study gives a deeper understanding of factors that influence events, changes and growth within an organisation (Rubin 2000, Mampe 2013, Tanye 2014, Luthuli 2017). A case study has the advantage of allowing the research to discover a complex set of decision making and to report on the effects of the decisions over time, making it appropriate for this research. In this study, the target population consisted of forty-eight records handlers (doctor, nurses), twenty-four records managers/medical clerks and fifty patients. Of these, a total of forty-two records handlers responded to the questionnaire. The patients at the public hospital were conveniently sampled as and when they entered the hospital and twenty were selected and interviewed. In addition, twenty-two people (medical records clerks and a manager) were interviewed. Data from interviews was thematically categorised and qualitative narratives presented. Some basic descriptive quantitative analyses were made using Google Forms software.

\section{Findings and discussions}

The findings of the study are based on the following themes:

- compliance with records management procedure and tools in accordance with service delivery;

- Records Management Unit (RMU) assistance and location of patient files;

- location and length of time for retrieval of medical records;

- $\quad$ patient satisfaction with records management at the public hospital; and

- impact of records management structure on service delivery. 


\subsection{Compliance with procedure and tools in accordance with service delivery}

In this study, the records handlers were asked if they thought current records management in their department aided service delivery. Further to that, patients were interviewed to find out if they were happy with the service being provided to them by the hospital. The records handlers at the Ngwelezana Public Hospital reported that the current records management tools and procedures did aid health service delivery, even though the manual system was time-consuming and laborious. They mentioned that they were understaffed, making it difficult to delivery good records management for quality health service to the community. The researchers observed that only two people worked at a time to service the many people in the public hospital. The large number of patients make it difficult for just two employees to serve everyone waiting in the queue. One records handler confirmed this obstacle when interviewed. He also expressed concern about the movement of the medical files:

When doctors request a file, we number the whole file so that no pages will be missing. Then again when the doctor is finished with the file, we check if all the files are not missing. [When] the appointment is made, then we request that particular file. It can be from our file room and remain in the queue for a long time to come...

The records handlers in the public hospital indicated that, at times, they find the information they are looking for, but this is not always the case, as eleven respondents indicated. Three respondents said they never find what they are looking for, while one reported sometimes finding the information in question. These findings show that poor records management delivery is still an issue in the public hospital where, owing to the use of a poor manual records management system, much time is spent locating files. The study confirmed that patients at the public hospital spend a lot of time in long queues waiting for files to be retrieved so that they can be attended to by medical personnel. The delays were because, as mentioned, only two records handlers were servicing up to sixty users. In addition, the file tracking system used at the public hospital is fraught with challenges. In some cases, patients have to bear the cost of buying their own file folders when their files are lost. In the Limpopo province, Marutha (2011) revealed similar challenges of poor record keeping that hampered health service delivery to people in the area. Pyrene (2015) found similar challenges related to misfiling and missing patient folders which sometimes led to the creation of new patient folders, thus undermining service delivery at the Victoria Public Hospital in the Eastern Cape province.

\subsection{Required assistance from the Records Management Unit for patients}

The Records Management Unit (RMU) is the 'face' of the hospital. It is where the first visit begins and hospital service rating starts. The users were asked how long it took them to get the assistance they were looking for from the RMU. Of the respondents that answered this question, four said it takes days, thirteen said that it takes hours, and only three said it takes minutes. During the interview, some patients indicated that sometimes three to four hours pass without any help being provided, as captured below.

Transcript (in IsiZulu): "Selokhu fike la ngo 5:30 kodwa u 8 manjena ngilinde ukuthi bakhiphele I fayela lami, okubuhlungu ngane yami ulayini uyashiya ekubone udokotela, sengofana nomuntu ofike emvakwesikhathi."

Translation: "I've been here since 5:30 am, but up until now I have not received my file and it's 8 o'clock. What makes me sad is that, to the doctor, it will be as if I came late and I did not meet the appointment time."

Clearly, it takes a long while for patients in the public hospital to receive the required information on time. This issue shows that the Ngwelezana Hospital public hospital still needs to improve its services to patients. Ngoepe (2008), Marutha (2011), Katuu (2015) and Pyrene (2015) all pointed out that there is a need for improvement in the service provision in public hospitals in South Africa.

\subsection{Location and length of time for retrieval of medical records}

This study sought to establish the frequency at which records were created and used. Records users were asked to indicate the frequency at which the records were required. The records handlers were asked to indicate what happens when a patient's file is not located in its normal place. The records handlers indicated that, for purposes of continuation of a patient's health record, if patient files are not found, duplicates of records are made. The patients agree to the creation of a new record when an old one cannot be found. The records handlers voiced their concerns about this process, saying that there 
are instances when the new file is lost and the whole process has to be repeated. One of the records handlers described the tedious process to create the recovery file, saying:

Transcript (in IsiZulu): "Siqala sibuze ukuthi isiguli sagcina nini esibhedlela siphinde sibuze yalishiyaphi ifayela ngaphambi kokuthi senze ifayela elisha, mase sidlulisela udaba kumphathi omkhulu. Uma umphathi eluthatha udaba inombolo yefayela ibe isinikwa umphathi ukuthi sibhekisise."

Translation: "First we interview the patient: where was the file last used? If the file is not located, we refer to the supervisor while keeping the patient in the loop. If the supervisor takes over, the duplication will be done and a file number will be given to the supervisor...and, you see, we go over and over again and it is tedious."

During the interview, it was found that files are lost by patients in an attempt to avoid the consultation fee payment (R35.00); some patients even try to steal their files to avoid paying. Another issue is that the public hospital has limited space to keep records, resulting in the loss of some records. The records handlers stated that:

Transcript (in IsiZulu): "Sometimes we end siwampitshile amafali kwamanye lokho kwenza egcine eselahleka engasatholakali."

Translation: "Due to space being limited, we end up putting files in between other files and that causes the file to be misplaced when it's time to look for it...and then it is not found because we were trying to squeeze it in."

The implication from this study is that the public hospital is faced with file loss challenges due to space shortages and theft from users. This, in turn, affects delivery of quality health services.

\subsection{Patient satisfaction with records management at the public hospital}

The majority of respondents from Ngwelezana Hospital said that they were not happy with the way their records were managed at the Outpatient Department (OPD). The OPD is responsible for all files at the hospital and is where records are managed by clerks. The study revealed patients finding their files covered in dust or torn; sometimes folios or entire files were missing and patients were not told where they could be located. The clerks required patients themselves to buy new folders when their files were full. The patients concurred that it was their (the patients') responsibility to buy folders for their files to prevent their records from being lost. One respondent indicated that:

Transcript (in IsiZulu): "Mina ifayela lami engalimalangalo engoziniyemoto lalahleka akazengikwazingisho ukuclaimer from road accident fund ngoba ngangingasenayo imininingwano ngokulimalakwami."

Translation: "My file went missing from the hospital. I was supposed to use it to claim from the Road Accident Fund. Because my file was missing, I did not have it to back up that I was really involved in a car accident. I was unable to claim because there was nothing to back up my story."

These findings imply that, at this public hospital, there are still various challenges when it comes to records service delivery. In addition, from the researchers' observations, the file room was not conducive to the storage of medical records: the room had high temperatures and an unsuitable file classification system. One of the interviewees said:

Transcript (in IsiZulu): “Inkinga nje esinaso is'space ngoba ngikhuluma nawe asazi sobekakuphi u 2016 asiphathike u 2017 ngoba onkelamafayela ala ekakabisesime nisokuthi angakhishwa khonasizothola ispace."

Translation: "The problem we have is the space. As I am speaking to you now, we do not know where we are going to put 2016. I don't know about 2017. It is even worse because all these files are not yet mature enough to be discarded in order to give us space."

Poor records keeping affects the functioning of the entire organisation, leading to poor health service provision (IRMT 1999). The studies by Ngoepe (2004), Marutha (2011) and Pyrene (2015) all reported that poor records management was an issue in public hospitals in South Africa.

\subsection{Impact of records management structure on service delivery}

The records handlers were asked to indicate what type of records management system the hospital had adopted. There was disparity in the responses as five records handlers and medical clerks confirmed the use of a centralised system in managing records; sixty-three said they used a decentralised system; while twenty were not sure of the system being used. 
These inconsistencies indicate that the staff that handle records are not professionally conversant with the records management system in place. The researchers observed that even some records handlers who had worked at the facility for a long time, did not know what system was in place. Observations, however, revealed that the hospital used a centralised system in managing its medical records. The researchers also observed that the hospital managed only the paper-based records, space again being an issue. Owing to the space problem, the hospital was using an outside container that they referred to as khulukuthu ('dumping area'), ironically implying that medical records were simply discarded there.

During their follow-up visits to the hospital, patients were asked about where they had collected their files. Respondents indicated that their records were normally kept at the OPD, referred to by some as the 'front desk'. The hospital administrator mentioned that all files are collected from other units by the clerks daily so that, when patients arrive, files can be fetched from the OPD. There is a sign placed in the window indicating that follow-up patients should use the second cubicle; this sign sometimes creates the problem of patients with no serious condition opening new files and having to wait in long queues unnecessarily. This study established that carrier cards in public hospitals are still in use and effective, although they can be used by anyone to retrieve a file. The study further revealed that, since all medical records were specifically centralised at the OPD, this affected file retrieval for follow-up visits. One records handler explained the defects of this centralised approach and how it affects file retrieval and follow-up visits, as follows:

The OPD is a 'representative' of the hospital; if patients have a bad experience at the OPD, they blame the whole hospital as it works as a 'face' of the hospital. Due to a poor records management structure in place where everything is centralised in one place, there are very long queues every day and the patients end up opening new files each and every time they come to the hospital to avoid long queues. Follow-up on these files is a nightmare.

Pyrene (2015: 109) found that the Victoria Hospital in the Eastern Cape had a centralised system and faced similar challenges in their records management functions. Similarities were identified by authors such as Kerry (1999), Norden (2004) and Pyrene (2015) who observed that the use of the manual system in the public hospital and the use of registers when doing file tracking of the current records management system was time-consuming. This study confirmed that the challenges faced by the public hospital in the OPD included file loss, missing folios, torn files, delayed diagnosis and long lines. Studies by Kerry (1999) at the Emtshezi District in KZN, Norden (2004) at the Tzaneen Municipality in Limpopo, and Marutha (2011) at the Limpopo Public Hospital, all reported similar challenges. This therefore confirmed that issues outlined are not new, but, rather, decade-old issues that simply have not been addressed. The indication is that integration of Information and Communication Technologies (ICTs) may be key to increasing the efficiency of the records system at the hospital.

\section{Recommendations}

The study makes the following recommendations with regards to effective records management practices for efficient public service delivery at the Ngwelezana Public Hospital:

\subsection{Compliance with records management procedures and tools in accordance with service delivery}

The study revealed that there is a lack of medical records management policy, procedures and tools within the Ngwelezana Hospital to govern records internally. It therefore recommends the following:

- The public hospital should request guidance from the National Archives and Records Services (NARSA) on the implementation of an effective medical records management programme.

- Training workshops be required for records handlers to help them to understand their roles and responsibilities in good medical records management practices and standards.

- The Ngwelezana Hospital should put Batho Pele principles into practice at all times by placing patients' needs first by giving them sufficient and timely information when serving them.

\subsection{RMU assistance and location of patient files}

The study established that various challenges encountered in the Ngwelezana Hospital include the time spent in the retrieval of patient files or folders. The following is recommended:

- A file tracking system, driven by better records, should be implemented for the easy retrieval for an efficient service delivery.

- Movable shelves should be used to save space and allow for easy retrieval.

- Appropriate records management related software and technology should be utilised to speed up the service. 
- Records managers (referred to as Unit Managers in Ngwelezana) should apply for advanced studies in archives and records management.

\subsection{Satisfaction with records management at the hospital}

The study established that patients and users were not happy with the way the files were handled by the records handlers at the Ngwelezana Hospital, including the poor infrastructure for the management of records. The following is recommended:

- The hospital management should put in place effective service monitoring practices to evaluate the level of performance in terms of how service is rendered.

- There should be a visible suggestion box for patients to make suggestions regarding the records service delivery improvements.

- The whole RMU infrastructure should be restructured to help facilitate effective records management.

\subsection{Impact of records management structure on service delivery}

The study revealed a lack of understanding of the nature of the centralised records systems and found that the system was not effective in the retrieval of files. The following is recommended:

- Ngwelezana Hospital should review its centralised manual records management system needs to improve the filing system, the capacity of designated staff, skills and training, and administrative leadership.

- There is a need to adopt and integrate ICTs in records management functions so as to increase the efficiency of the records system at the hospital.

\subsection{Responsibility for the management of records}

The study established that the clerks and administrators who were responsible for records management at the Ngwelezana Hospital were not qualified to carry out a records management function. The following is recommended:

- The public hospital should employ qualified records handlers for the records management function.

- Records management units should be monitored at least once a year;

- In-house training should be adopted and be facilitated by qualified records managers from NARSA or other reputable institutions.

- To motivate records managers, the hospital should work closely with NARSA to restore the certification of performance.

\section{Conclusion}

This paper presents empirical findings of an investigation into the implementation of good records management services and the extent to which it contributes to corresponding citizen satisfaction of good health delivery at the community level. The ultimate goal was to understand the scale and dimension of good medical records management in determining issues of accountability in health care for citizens at local or community level in the quest for optimal health service delivery and governance. The study investigated service delivery in accordance with the Batho Pele principle in records management at the Ngwelezana Public Hospital. The findings revealed that the compliance with records management tools and procedures is still a challenge; just as the records management policy to govern the records management function was absent. The health service delivery system in accordance with the Batho Pele principle was not being fulfilled, with many respondents citing weaknesses that included:

- delay of health service to patients that depends on effective and efficient file retrieval;

- lack of awareness of records management;

- lack of qualified records managers;

- low staff awareness of and quality assurance towards administrative record keeping policies and procedures;

- insufficient budget for record keeping tools;

- lack of job description relating to the records management function; and

- lack of awareness of the NARSA records management guideline.

On the whole, the evidence showed that poor records management could undermine service delivery and therefore transparency and accountability in health delivery. The study recommends a framework for good records management governance, a recordkeeping system, records management technology and infrastructure, records archival processes, and records management human resource capabilities. 


\section{References}

Abankwa, R. M. 1999. The impact of computerizing medical records on the quality of health care: a comparative study of selected hospitals in Botswana. MLIS thesis. University of Botswana.

Adjei, E. 2000. The management of medical records in government hospitals in Ghana: an agenda for reform. PhD thesis. University of London.

Asunmo, A.O. and Yaya, J.A. 2016. Management and preservation of health records in some selected hospitals in Lagos state, Nigeria. International Journal of Information Research and Review, 3(1): 1601-1605.

Chachage, B. and Ngulube, P. 2006. Management of business records in Tanzania: an exploratory case study of selected companies. SA Journal of Information Management, 8(3): 3-7.

Chikuni, P.R. 2006. The management of medical records at Gwanda Provincial Hospital, Zimbabwe. Master's thesis. University of Botswana.

Dunlay, S.M., Alexander, K.P., Melloni, C., Kraschnewski, J.L., Liang, L., Gibler, W.B., Roe, M.T., Ohman, E.M. et al. 2008. Medical records and quality of care in acute coronary syndromes: results from CRUSADE. Archives of Internal Medicine. 1681(5):1692-1698.

Green, M.A. 2011. Essentials of health information management: principles and practices. Clifton Park, NY: Delmar, Cengage Learning.

Hajavi, A., Azar, F.E, and Meidani, Z. 2005. Medical records standards in selected countries and Iran: a comparative study. New Journal (Institute of Health Record \& Information Management), 46(1): 4-6.

International Organization for Standardization (ISO). 2016. 2016. Information and documentation - Records management. ISO 15489-1. Geneva: ISO.

International Records Management Trust (IRMT). 1999. Managing hospital Records. London: International Records Management Trust. [Online]. http://www.irmt.org/documents/educ_training/public_sector_rec/IRMT_hospital_recs.doc. (20 March 2016).

International Records Management Trust (IRMT). 2009. Understanding the context of electronic records management. London: International Records Management Trust.

Katuu, S.A. 2015. Managing records in South African public health care institutions: a critical analysis. PhD thesis. University Of South Africa.

Kemoni, H. N. 2007. Records management practice and service delivery in Kenya. PhD thesis. University of KwaZuluNatal.

Kerry, T. P. 1999. Improving the use of a patient-retained medical records in Emtshezi sub-district. Master's thesis. Medical University of South Africa.

Khoza, T., 2008. Dead baby's records missing. News24. [Online]. http://www.news24.com/SouthAfrica/News/Deadbabys-records-missing-20080707. (10 October 2016).

Kumar, R. 2005. Research methodology: a step-by-step guide for beginners. London: Sage.

Luthuli, L.P. 2017. Medical records management practices in public and private hospitals in Umhlathuze Area, South Africa. Master's thesis. University of Zululand.

Mampe, G. 2013. The role of records management in service delivery in Botswana: case study of the Department of Corporate Services in the Ministry of Health. Master's thesis. University of Botswana.

Marutha, N. S. 2011. Records Management in support of service delivery in the public health care sector of the Limpopo Province in South Africa. Master's thesis. University of South Africa.

Marutha, N.S. 2016. A framework to embed medical records management into the healthcare service delivery in Limpopo province of South Africa. PhD thesis. University of South Africa.

Mayanja, R. 2005. Decentralised health care services delivery in selected districts in Uganda. Master's thesis. University of Western Cape.

Moatlhodi, T.M. 2014. Assessment of E-records readiness at the Ministry of Labour and Home Affairs Headquarters in Botswana. Masters thesis. University of Botswana.

National Archives of South Africa Act, No. 43 of 1996. 1996. [Online]. http://www.unesco.org/culture/natlaws/media/pdf/southafrica/southafrica_act1996_engorof.pdf (21 March 2016).

National Health Act, No. 61 of 2003. 2004. [Online]. Act.co.za/national-health-act-2003/index.html (11 September 2016).

Ngoepe, M. 2004. Accountability, transparency and good governance: The National Archives and Records Service of South Africa's role in helping government to better service delivery. LIASA's 7th Annual Conference in Polokwane, South Africa (27).

Ngoepe, M. 2008. An exploration of records management trends in the South African public sector: a case study of the Department of Provincial And Local Government. Master's thesis. University of South Africa.

Ngulube, P. 2012. The nature and accessibility of e-government in Sub-Saharan Africa. [Online]. http://www.africainfoethics.org/pdf/african_reader/23\%20ICIE\%20Chapter\%2016\%20page\%20157-166.pdf (20 June 2016).

Norden, A. L. 2004. Patients' thoughts on patient retained medical records. Master's thesis. Medical University of South Africa.

Protection of Personal Information Act, No. 4 of 2013. 2013. [Online]. http://www.justice.gov.za/legislation/acts/2013004.pdf. 
Public Service Commission 2012. Report on the assessment of the effectiveness of the Batho Pele Policy in public service delivery (BPP report assessment). [Online]. http://www.psc.gov.za/documents/reports/2014/BATHO\%20PELE\%20NEW\%20250\%20by\%20175.pdf.

Pyrene, M.B. 2015. The management of records for healthcare service delivery at the Victoria Public hospital in the Eastern Cape Province in South Africa. Master's thesis. University of Fort Hare.

Rubin, A. 2000. Standards for rigor in qualitative inquiry. Research on Social Work Practice, 10(2): 173-179.

Schalk, O. 2003. The Batho-Pele programme and policy making in the North West Province. Potchefstroom: North-West University.

Shepherd, E and Yeo, G. 2003. Managing records: a handbook of principles and practice. London: Facet.

South Africa. Department of Public Service and Administration. 1997. White Paper on transforming public service delivery (Batho Pele White Paper) (No. 1459 of 1997). Pretoria: Government Printer.

Thanye, K.G. 2014., An assessment of architectural records appraisal practices at the Gaborone city council. Master's thesis. University of Botswana.

Wong, R.E.X. and Bradley, E.H. 2009. Developing patient registration and medical records management system in Ethiopia. International journal for Quality in Health Care, 21(4): 253-258. 